\title{
Theoretical Investigation of Hydrogen Absorption Properties of Rhodium-Silver Alloys
}

Tomoe Yayama* $^{1,2,{ }^{\dagger}}$, Takayoshi Ishimoto ${ }^{1,2}$, and Michihisa Koyama* 1,2,3

1) INAMORI Frontier Research Center, Kyushu University, 744 Motooka, Nishi-ku, Fukuoka 819-0395, Japan

2) CREST, Japan Science and Technology Agency, K's Goban-cho, Goban-cho 7, Chiyoda-ku, Tokyo 102-0076, Japan

3) International Institute for Carbon-Neutral Energy Research (WPI-I2CNER), Kyushu University, 744 Motooka, Nishi-ku, Fukuoka 819-0395, Japan.

\section{Corresponding Author}

* To whom the correspondence should be addressed:

YAYAMA.Tomoe@nims.go.jp, koyama@ifrc.kyushu-u.ac.jp

\section{Present Addresses}

$\dagger$ Present address: National Institute for Materials Science (NIMS),

1-1 Namiki, Tsukuba, Ibaraki 305-0044, Japan 


\section{ABSTRACT}

The density of states and the $\mathrm{H}$ absorption energy of $\mathrm{Ag}_{\mathrm{x}} \mathrm{Rh}_{1-x}$ alloys were theoretically investigated by the first-principles method. The electronic structure of the alloys near the Fermi edge was similar to that of $\mathrm{Pd}$, which is known as hydrogen-storage metal, and this indicated the electronic state at the part plays important role to determine the $\mathrm{H}$ absorption property. The results showed that the $\mathrm{H}$ absorption into the $\mathrm{Ag}_{\mathrm{x}} \mathrm{Rh}_{1-x}$ alloys was thermodynamically stable and the trend of composition dependence agreed well with the experimental observation. Considering the atomic configuration of alloys, homogeneous structure is found to be a key in the emergence of $\mathrm{H}$ absorption nature in this alloy system.

\section{KEYWORDS}

Hydrogen absorption alloys, Electronic structures, Density functional theory

\section{MAIN TEXT}

\section{Introduction}

The transition metals such as $\mathrm{Pd}, \mathrm{Pt}$ and other elements are known as good catalysts or the $\mathrm{H}$ absorption metals. It is generally known that alloying in the atomic level brings the functionality different from that of mono-element materials ${ }^{1-11}$. Recently, Kusada et al. ${ }^{12}$ successfully fabricated through a novel synthesis method the homogeneously mixed alloy nanoparticle of Rh and $\mathrm{Ag}$, which is well known as the thermodynamically immiscible combination in the bulk ${ }^{13}$. It was found that the Ag-Rh alloy systems absorb the hydrogen like Pd locating between $\mathrm{Rh}$ and $\mathrm{Ag}$ in the periodic table, while bulk $\mathrm{Rh}$ or $\mathrm{Ag}$ do not absorb hydrogen. The composition 
dependence of the amount of the absorbed $\mathrm{H}$ is also observed: $\mathrm{Ag}_{0.5} \mathrm{Rh}_{0.5}>\mathrm{Ag}_{0.4} \mathrm{Rh}_{0.6}>$ $\operatorname{Ag}_{0.7} \mathrm{Rh}_{0.3}$. The work proved that we can arbitrarily reproduce or control the material property with the alloys of which combination of the elements and the compositions are infinity. The correlation between the $\mathrm{H}$ absorption property and the electronic structure is well discussed the former literatures by Klein and Papaconstantopoulos et al. ${ }^{14-16}$ To understand the origin of Pd like property observed in Ag-Rh alloy systems, Seo et al. theoretically studied the $\mathrm{H}$ absorption and electronic structure of the $\mathrm{Ag}_{0.5} \mathrm{Rh}_{0.5}$ alloy using a super cell (layered) structure. ${ }^{17} \mathrm{We}$ also have studied the electronic structure of $\mathrm{Ag}_{0.5} \mathrm{Rh} 0.5$ alloy both experimentally and theoretically to find the similarity between Ag-Rh alloys and Pd in the electronic states near the Fermi level. ${ }^{18}$ As a next step to understand the unique properties of $\mathrm{Ag}_{0.5} \mathrm{Rh}_{0.5}$ alloy, we theoretically investigated the hydrogen absorption properties in this study. Hydrogen absorption occurs through gas phase diffusion, adsorption, and dissociation of hydrogen molecules followed by migration of atomic hydrogen into the interstitial sites of metals. Among those processes, we focus on the state of absorbed hydrogen in the metal, which is observed in the preceding experimental study. ${ }^{12}$ In this manuscript, to discuss the detail influence of alloy compositions and configurations on the electronic structures and $\mathrm{H}$ absorption properties of $\mathrm{Ag}_{x} \mathrm{Rh}_{1-x}(0 \leq x \leq 1)$

alloys, the computational work based on the density functional theory (DFT) calculations with various configuration models is presented. 


\section{Computational Method and Calculation Details}

We employ the alloy models made from the rhombohedral cells consisting of the eight metal atoms of $\mathrm{Rh}$ and $\mathrm{Ag}$, i.e. $\mathrm{Ag}_{\mathrm{x}} \mathrm{Rh}_{1-x}$ alloys $(x=0,0.125,0.25,0.375,0.5,0.625,0.75,0.875,1) . \mathrm{A}$ small sized model is chosen to avoid the complexity of many possible configurations in larger model and to concentrate on the discussion of the local configuration. Figure 1 shows the three non-equivalent configurations for the $\mathrm{Ag}_{0.5} \mathrm{Rh}_{0.5}$ alloy. The non-equivalent configurations contain a different set of octahedral sites. For example, there are three configurations for Rh0.5Ag 0.5 alloy model as shown in Fig. 1. For configuration 1, there are eight octahedral sites that consist of 3 $\mathrm{Rh}$ and $3 \mathrm{Ag}$ atoms $\left(\mathrm{Ag}_{3} \mathrm{Rh}_{3}\right.$ site $)$. For configuration 2, there are three types of octahedral site: Two sites consist of $4 \mathrm{Rh}$ and $2 \mathrm{Ag}$ atoms $\left(\mathrm{Ag}_{2} \mathrm{Rh}_{4}\right)$, four are $\mathrm{Ag}_{3} \mathrm{Rh}_{3}$ and the remaining two are $\mathrm{Ag}_{4} \mathrm{Rh} \mathrm{h}_{2}$. Configuration 3 has four $\mathrm{Ag}_{2} \mathrm{Rh}_{4}$ and four $\mathrm{Ag}_{4} \mathrm{Rh}_{2}$ sites. To classify the configurations, we analyzed the homogeneity of the alloys. As an index for homogeneity of the alloys, we used the standard deviation of the composition, i.e. the variation of the local composition of the octahedral sites from the overall alloy composition. Thus, the standard deviation $\sigma$ is obtained by following equation:

$$
\sigma=\sqrt{\sum_{\text {site }}(c-x)^{2} \cdot n_{\text {site }}} \text {. }
$$

$c$ and $x$ are the compositions of Rh for the site and the whole alloy, respectively. $n_{\text {site }}$ is the number of the sites. The components and the numbers of the sites for each alloy and the standard deviation are shown in Table 1. For the configuration 1 of $\operatorname{Ag}_{0.75} R_{0.25}$, there are four $\operatorname{Ag}_{5} \mathrm{Rh}_{1}$ sites $\left(n_{\text {site }}=4\right.$ and $\left.c=1 / 6\right)$ and four $\mathrm{Ag}_{4} \mathrm{Rh}_{2}$ sites $\left(n_{\text {site }}=4\right.$ and $c=$ ca. $\left.1 / 3\right)$. As a result, the 
standard deviation is obtained as 0.083 . The configurations are numbered in the order of decreasing homogeneity.

We calculated the $\mathrm{H}$ absorption energy for $\mathrm{Ag}_{x} \mathrm{Rh}_{1-x} \mathrm{H}_{y}(y=0.125,1.0)$ i.e. the models that contain one or eight $\mathrm{H}$ atoms in interstitial octahedral sites. The $\mathrm{H}$ absorption energy $\left(\Delta E_{\mathrm{H}}\right)$ is calculated by the following equation:

$\Delta E_{H}=\left\{E_{\mathrm{M}-\mathrm{H}}-\left(E_{\mathrm{M}}+n / 2 \cdot E_{\mathrm{H} 2}\right)\right\} / n$.

In this work, zero-point energy is not considered. For all the total energy calculations, we used the DFT program with the projector augmented wave method, as implemented in the Vienna $\mathrm{Ab}$ initio Simulation Package (VASP). ${ }^{19-22}$ The Perdew-Burke-Emzerhof ${ }^{23}$ functional with a generalized gradient approximation is used for the exchange and correlation interactions. For the plane-wave basis sets, cut-off energies of 400 and $700 \mathrm{eV}$ are used for geometry optimization and density of states (DOS) calculations, respectively. The convergence threshold for selfconsistent field calculations is $1.0 \times 10^{-5} \mathrm{eV} /$ atom. After carefully checking the energy convergence with the parameter such as cut-off energy or the number of k-points, we found that the energy fluctuation is less than $\sim 10^{-3} \mathrm{eV}$ when the k-points sampling of $10 \times 10 \times 10$. We thus selected 14 x 14 x 14 k-points sampled by the Monkhorst-Pack gridding method. ${ }^{24}$ The cell and atomic positions are optimized in advance by a conjugate gradient method with tolerances of 1.0 x $10^{-4} \mathrm{eV} /$ atom. 


\section{Results and Discussions}

\section{A. Density of states}

In Fig. 2, total and partial DOSs for $\mathrm{Ag}_{\mathrm{x}} \mathrm{Rh}_{1-x}$ are shown. The longitude is the total energy with the origin at the Fermi energy $\left(E_{\mathrm{F}}\right)$. The results for the configuration 1 for each composition are presented. The DOS for Pd is also drawn in gray broken line for reference. The shape of DOS of Rh and Ag metals are different; In Fig. 2 (a) DOS of Rh is rich in the energy range from ca. +1 to $-6 \mathrm{eV}$ while that of $\mathrm{Ag}$ (Fig.2 (i)) is rich in the range from ca. -3 to -6 . When they form alloy, we can see that DOS's of $\mathrm{Rh}$ and Ag are separately located at higher and lower energy levels, respectively. While the bottom edge of the band almost keep constant just under $E-E_{\mathrm{F}}=-6 \mathrm{eV}$, the top edge becomes lower with increasing the content of Ag. In the preceding study, the valence band structure of $\mathrm{Ag}_{0.5} \mathrm{Rh}_{0.5}$ is carefully investigated on the basis of hard X-ray photoelectron spectroscopy measurements and DFT calculations ${ }^{18}$. The striking similarity of electronic structure of $\mathrm{Ag}_{0.5} \mathrm{Rh}_{0.5}$ alloy with $\mathrm{Pd}$ in the $E-E_{\mathrm{F}}$ range of 0 to $-3.5 \mathrm{eV}$ was found. In the present work, we can see the composition dependence of the shape of the DOS for $\mathrm{Ag}_{\mathrm{x}} \mathrm{Rh}_{1-\mathrm{x}}$. The Rh or Ag rich alloys, i.e. $x=0.125$ and 0.875 (Fig.2 (b) and (h)) show the DOS's reflecting the features of $\mathrm{Rh}$ and $\mathrm{Ag}$ metals, respectively. On the other hand, the medium composition, $x=$ 0.25, 0.375, 0.5, (Fig.2 (c)-(e)) provides the different electronic structures from simple summation of pure Rh and Ag and the topmost peaks of the DOSs locate at EF. In Fig.2 (f) and (g) $(x=0.625$ and 0.75$)$ the cases with relatively high $\mathrm{Ag}$, the DOS near $E_{\mathrm{F}}$ is quite small. the Comparing the DOS's of $\mathrm{Ag}_{\mathrm{x}} \mathrm{Rh}_{1-\mathrm{x}}$ alloy with that of $\mathrm{Pd}, \mathrm{Ag}_{0.5} \mathrm{Rh}_{0.5}$ shows a high similarity especially at the Fermi edge vicinity as reported in the preceding work $^{18}$ while those of $\mathrm{Ag}_{0.125} \mathrm{Rh}_{0.875}$ and $\mathrm{Ag}_{0.875} \mathrm{Rh}_{0.125}$ are apparently different from that of $\mathrm{Pd}$. We can see that the similarities of other intermediate compositions lie in between. 


\section{B. H absorption energy}

$\mathrm{H}$ absorption energies are listed in Table 2. The results for $\operatorname{Ag}_{x} \mathrm{Rh}_{1-x} \mathrm{H}_{y}(y=0.125,1.0)$ are shown. At the column of the site, the label of "Ag6" means that one $\mathrm{H}$ atom is located at the sites consists of six Ag atoms. The label of "all" shows the case that eight $\mathrm{H}$ atoms occupy the all octahedral sites of the alloy. The negative values, which indicate the stable $\mathrm{H}$ absorption, are shown as bold. The definitions of configuration, compositions of alloy and sites are the same as those for Table 1.

The $\mathrm{H}$ absorption energy for $\mathrm{Rh}$ and $\mathrm{Ag}$ are positive, while, the $\mathrm{H}$ absorption energy of $\mathrm{Ag}_{\mathrm{x}} \mathrm{Rh}_{1-x}$ depends on the sites and the composition of alloys. We can see the negative values in every composition of Ag-Rh alloy models, at least for one octahedral site. This means that stable sites emerge as results of alloying. Throughout the results, the sites containing more $\mathrm{Rh}$ atoms are more stable than Ag-rich sites in the same alloy, indicating the importance of local composition on the stability of hydrogen. The $\mathrm{H}$ absorption energies with the eight $\mathrm{H}$ atoms in the model are shown in Fig. 3. In Fig. 3, the values of the most stable configuration for the composition are shown in the filled squares and the others are open. As the composition of $\mathrm{Ag}$ increases in $\mathrm{Ag}_{\mathrm{x}} \mathrm{Rh}_{1-\mathrm{x}}$ alloy, the stability of the hydrogen increases showing the maximum near the 1:1 composition, followed by the decrease of hydrogen stability with further increase in Ag composition. We can see the composition dependence of the energy and the minimum value is found for $x=0.375$ followed by $x=0.5$. Furthermore, the values of $0.25 \leq \mathrm{x} \leq 0.625$ in configuration 1 are negative. When the hydrogen-metal system is at the equilibrium, alpha (low $\mathrm{H}$ density) phase is in the equilibrium with beta (metal-hydride) phase. The $\mathrm{H}$ concentration under equilibrium is determined by common tangent of Gibbs energy for both phases. Therefore, the more stable beta phase may result in the higher hydrogen to metal ratio. Additionally we 
already observed that the preference of the Rh-rich sites for each composition. This indicates again that the local configuration surrounding $\mathrm{H}$ atom strongly affect the $\mathrm{H}$ absorption properties even in the metallic system where valence electrons are delocalized. In experiment, the composition dependence of the solubility of $\mathrm{H}$ into $\mathrm{Ag}_{\mathrm{x}} \mathrm{Rh}_{1-\mathrm{x}}$ alloys indicated the better $\mathrm{H}$ absorption at the 1:1 composition than Ag-rich case. ${ }^{12}$ The trend of present results agrees well with the experimental observations. Considering the observed similarity of DOS's of $A g_{x} R h_{1-x}$ with that of Pd for alloy composition at around $x=0.5$, we can say that the similarity of DOS with $\mathrm{Pd}$ is well correlated with better $\mathrm{H}$ absorption properties of the alloy. We also analyzed the configuration effect on the stability of hydrogen. From Table 1, homogeneities, i.e. the standard deviation, of configurations 1-3 of $\mathrm{Ag}_{0.5} \mathrm{Rh}_{0.5}$ are $0,0.118$, and 0.167 , respectively. The $\mathrm{H}$ absorption energies of configurations $1-3$ of $\mathrm{Ag}_{0.5} \mathrm{Rh}_{0.5} \mathrm{H}$ are $-0.122,-0.093$, and $0.073 \mathrm{eV}$, respectively (see Table 2). This results clearly show that the higher homogeneity will lead to better $\mathrm{H}$ absorption properties. From our calculation results, we can say that the homogeneously mixed solid solution structure realized in the work by Kusada et al. ${ }^{12}$ is one important factor in the emergence of hydrogen absorption properties in the $\mathrm{Ag}_{\mathrm{x}} \mathrm{Rh}_{1-\mathrm{x}}$ alloy systems.

\section{Conclusion}

We calculated the $\mathrm{H}$ absorption energy and DOSs for $\mathrm{Ag}_{\mathrm{x}} \mathrm{Rh}_{1-x}$ alloys. It is found that every alloy has the sites for stable $\mathrm{H}$ absorption. From the DOS analyses, the similarity of the $\mathrm{Ag}_{\mathrm{x}} \mathrm{Rh}_{1-x}$ alloy and Pd in DOS near $E_{\mathrm{F}}$ was seen for the intermediate composition alloys. The $\mathrm{H}$ absorption energy depends on the sites and alloy composition. Throughout the results, the sites containing more $\mathrm{Rh}$ atoms are more stable than $\mathrm{Ag}$-rich sites in the same alloy composition, indicating the importance of local composition on the stability of hydrogen. For whole alloy, the most composition with better hydrogen absorption properties was found to be near 1:1. Rh-rich alloy 
shows better hydrogen absorption properties than Ag-rich one, which agrees well with the experimental observations. ${ }^{12}$ We also investigated the influence of alloy configuration on $\mathrm{H}$ absorption properties and found that the configuration with higher homogeneity shows better $\mathrm{H}$ absorption properties. From this finding, we can say that the homogeneously mixed solid solution structure realized in new synthetic process by Kusada et al. ${ }^{12}$ is an critical factor in the emergence of hydrogen absorption properties in the $\mathrm{Ag}_{x} \mathrm{Rh}_{1-x}$ alloy systems. 


\section{ACKNOWLEDGMENT}

The authors thank Profs. H. Kitagawa and H. Kobayashi for fruitful discussions and comments on this manuscript. Monthly meetings with Prof. S. Matsumura and the members of his laboratory refined and improved our ideas. Discussions with Prof. O. Yamamuro and the members of his laboratory are also gratefully acknowledged. This work is funded by CREST

(Core Research for Evolutional Science and Technology) of JST (the Japan Science and Technology Corporation). The activities of the INAMORI Frontier Research Center, Kyushu University are supported by KYOCERA Corporation.

\section{REFERENCES}

1. A. Maeland, and T. B.Flanagan, "X-Ray and Thermodynamic Studies of Absorption of Hydrogen by Gold-Palladium Alloys”, J. Phys. Chem. 69, (1965), 3575-3581.

2. P. E. A. Turchi, V. Drchal, J. Kudrnovský, "Stability and Ordering Properties of Fcc Alloys Based on Rh, Ir, Pd, and Pt”, Phys. Rev. B, 74, (2006), 064202-1-12.

3. F. P. Mena, J. F. DiTusa, D. van der Marel, G. Aeppli, D. P. Young, A. Damascelli, J. A. Mydosh, "Suppressed Reflectivity due to Spin-Controlled Localization in a Magnetic Semiconductor”, Phys. Rev. B 73, (2006), 085205-1-7.

4. T. S. Eagleton, J. Mallet, X. Cheng, J. Wang, C. Chien, P. C. Searson, "Electrodeposition of $\mathrm{Co}_{x} \mathrm{Pt}_{1-x}$ Thin Films", J. Electrochem. Soc. 152, (2005), C27-C31.

5. M. Łukaszewski, and A. Czerwiński, "Electrochemical Behavior of Palladium-Gold Alloys", Electrochim. Acta 48, (2003), 2435-3445. 
6. M. Yamauchi, R. Ikeda, H. Kitagawa, M. Takata, "Nanosize-Effects on Hydrogen Storage in Palladium", J. Phys. Chem. C 112, (2008), 3294-3299.

7. H. Kobayashi, H. Morita, M. Yamauchi, R. Ikeda, H. Kitagawa, Y. Kubota, K. Kato, M. Takata, "Nanosize-Induced Hydrogen Storage and Capacity Control in a Non-Hydride-Forming Element: Rhodium", J. Am. Chem. Soc. 133, (2011), 11034-11037.

8. H. Kobayashi, H. Morita, M. Yamauchi, R. Ikeda, H. Kitagawa, Y. Kubota, K. Kato, M. Takata, S. Toh, S. Matsumura, "Nanosize-Induced Drastic Drop in Equilibrium Hydrogen Pressure for Hydride Formation and Structural Stabilization in Pd-Rh Solid-Solution Alloys", J. Am. Chem. Soc. 134, (2012), 12390-12393.

9. H. Kobayashi, M. Yamauchi, H. Kitagawa, Y. Kubota, K. Kato, M. Takata, "Hydrogen Absorption in the Core/Shell Interface of Pd/Pt Nanoparicles" J. Am. Chem. Soc. 130, (2008), 1818-1819.

10. H. Kobayashi, M. Yamauchi, H. Kitagawa, Y. Kubota, K. Kato, M. Takata, “Atomic-Level Pd-Pt Alloying and Largely Enhanced Hydrogen-Storage Capacity in Bimetallic Nanoparticles Reconstructed from Core/Shell Structure by a Process of Hydrogen Absorption/Desorption” J. Am. Chem. Soc. 132, (2010), 5576-5577.

11. H. Kobayashi, M. Yamauchi, R. Ikeda, H. Kitagawa, "Atomic-Level Pd-Au Alloying and Controllable Hydrogen-Absorption Properties in Size-Controlled Nanoparticles Synthesized by Hydrogenreduction" Chem. Commun. (2009), 4806-4808. 
12. K. Kusada, M. Yamauchi, H. Kobayashi, H. Kitagawa, Y. Kubota, "Hydrogen Storage Properties of Solid-Solution Alloys of Immiscible Neighboring Elements with Pd", J. Am. Chem. Soc. 132, (2010), 15896-15898.

13. I. Karakaya, and W.T. Thompson "The Ag-Rh (Silver-Rhodhium) System”, Bull. of Alloy Phase Diagrams 7, (1986), 362-365.

14. B. M. Klein, E. N. Economou, D. A. Papaconstantopoulos, "Inverse Isotope Effect and the $x$ Dependence of the Superconducting Transition Temperature in $\mathrm{PdH}_{x}$ and $\mathrm{PdD}_{x}{ }^{\prime}$, Phys. Rev. Lett. 39, (1977), 574-577.

15. D. A. Papaconstantopoulos, B. M. Klein, E. N. Economou, L. L. Boyer, "Band Structure and Superconductivity of $\mathrm{PdD}_{x}$ and $\mathrm{PdH}_{x} ”$, Phys. Rev. B 17, (1978), 141-150.

16. D. A. Papaconstantopoulos, B. M. Klein, J. S. Faulkner, L. L. Boyer, "Coherent-PotentialApproximation Calculations for $\mathrm{PdH}_{x} ”$, Phys. Rev. B 18, (1978), 2784-2791.

17. D-H Seo, H. Shin, K. Kang, H. Kim, S. S. Han, "First-Principles Design of Hydrogen Dissociation Catalysts Based on Isoelectronic Metal Solid Solutions", J. Phys. Chem Lett. 5, (2014), 1819-1824.

18. A. Yang, O. Sakata, K. Kusada, T. Yayama, H. Yoshikawa, T. Ishimoto, M. Koyama, H. Kobayashi, H Kitagawa, "The Valence Band Structure of $\mathrm{Ag}_{x} \mathrm{Rh}_{1-x}$ Alloy Nanoparticles”, Appl. Phys. Lett. 105, (2014), 153109-1-5.

19. G. Kresse, and J. Hafner, “Ab Initio Molecular Dynamics for Liquid Metals”, Phys. Rev. B 47, (1993), 558-561. 
20. G. Kresse, and J. Furthmüller, "Efficient Iterative Schemes for Ab Initio Total-Energy Calculations Using a Plane-Wave Basis Set”, Phys. Rev. B 54, (1996), 11169-11186.

21. G. Kresse, and D. Joubert, "From Ultrasoft Pseudopotentials to the Projector AugmentesWave Method", Phys. Rev. B 59, (1999), 1758-1775.

22. P.E Blöchl, "Projector Augmented-Wave Method", Phys. Rev. B 50, (1994), 17953-17979.

23. J. P. Perdew, K. Burke, M. Emzerhof, "Generalized Gradient Approximation Made Simple”, Phys. Rev. Lett. 77, (1996), 3865-3868.

24. H. J. Monkhorst, and J. D. Pack, "Special Points for Brilloun-Zone integrations", Phys. Rev. B 13, (1976), 5188-5192. 


\section{FIGURES}

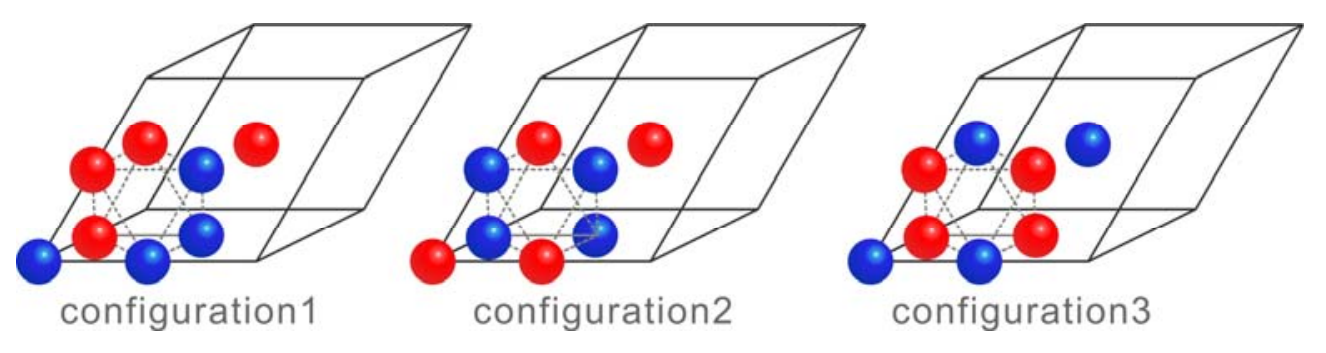

Figure1. Calculation models. Red and blue spheres show the $\mathrm{Ag}$ and $\mathrm{Rh}$ atoms. The figure shows the examples of $\mathrm{Ag}_{0.5} \mathrm{Rh}_{0.5}$ alloy that have three non-equivalent configurations. 

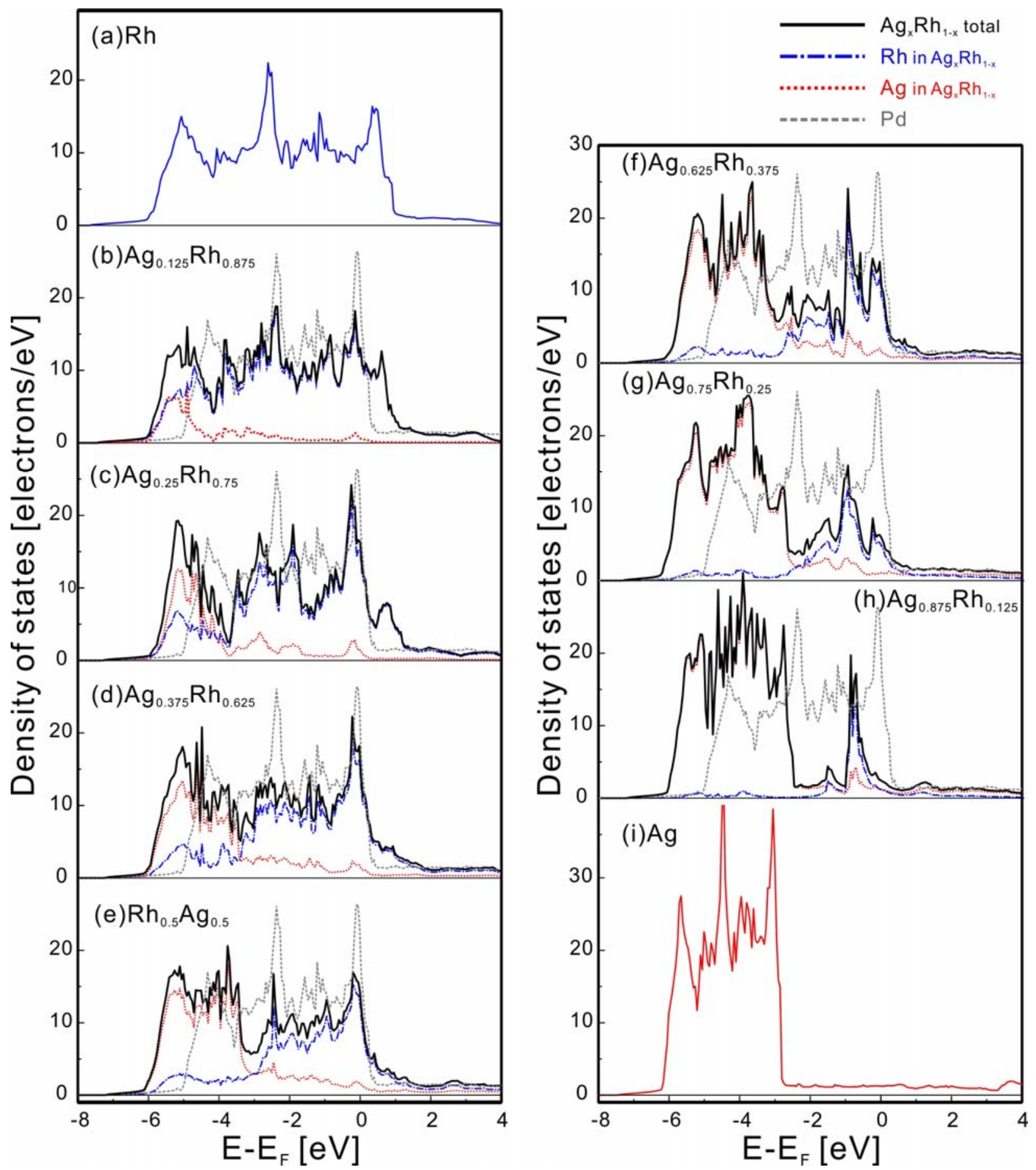

Figure 2. (a)-(i) Total and partial DOS for $\mathrm{Ag}_{x} \mathrm{Rh}_{1-x}$ alloys $(0 \leq x \leq 1)$. Black solid line shows the total DOS. Red dotted line and blue chain lines represent Ag and Rh partial DOSs, respectively. Pd DOS is shown in gray broken line as a reference. 


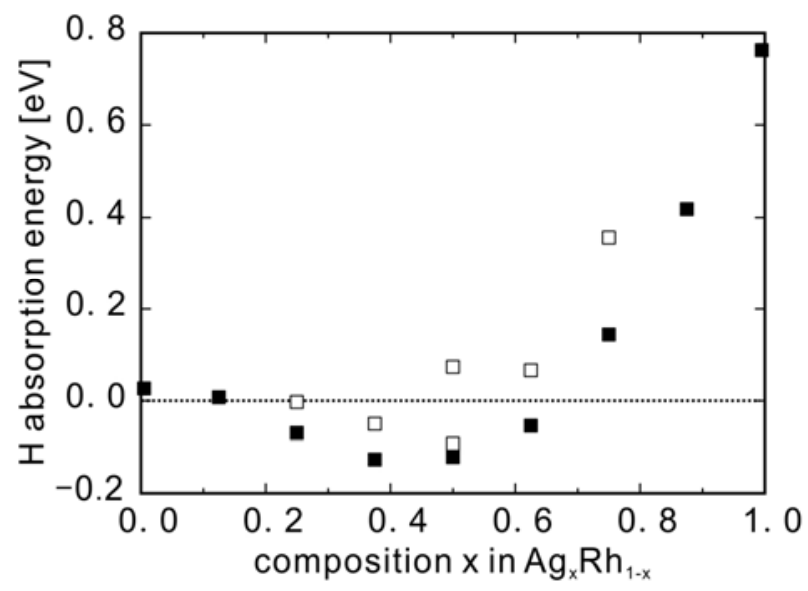

Figure 3. $\mathrm{H}$ absorption energy of $\mathrm{Ag}_{\mathrm{x}} \mathrm{Rh}_{1-\mathrm{x}}$ alloys with eight $\mathrm{H}$ atoms for every configuration. The most stable values among the configurations are represented in filled squares. 


\section{TABLES.}

Table 1. Configurations and homogeneity

\begin{tabular}{|c|c|c|c|c|c|c|c|c|c|c|}
\hline \multirow{2}{*}{$\begin{array}{l}\text { configu } \\
\text { rations }\end{array}$} & \multirow[t]{2}{*}{ sites } & \multicolumn{9}{|c|}{ Number of the sites and homogeneity } \\
\hline & & $\mathrm{Rh}$ & $\mathrm{Ag}_{0.125} \mathrm{Rh}_{0.875}$ & $\mathrm{Ag}_{0.25} \mathrm{Rh}_{0.75}$ & $\mathrm{Ag}_{0.375} \mathrm{Rh}_{0.625}$ & $\mathrm{Ag}_{0.5} \mathrm{Rh}_{0.5}$ & $\mathrm{Ag}_{0.625} \mathrm{Rh}_{0.375}$ & $\mathrm{Ag}_{0.75} \mathrm{Rh}_{0.25}$ & $\mathrm{Ag}_{0.875} \mathrm{Rh}_{0.125}$ & $\mathrm{Ag}$ \\
\hline \multirow{8}{*}{1} & $\mathrm{Rh}_{6}$ & 8 & 2 & & & & & & & \\
\hline & $\mathrm{Ag}_{1} \mathrm{Rh}_{5}$ & & 6 & 4 & & & & & & \\
\hline & $\mathrm{Ag}_{2} \mathrm{Rh}_{4}$ & & & 4 & 6 & & & & & \\
\hline & $\mathrm{Ag}_{3} \mathrm{Rh}_{3}$ & & & & 2 & 8 & 2 & & & \\
\hline & $\mathrm{Ag}_{4} \mathrm{Rh}_{2}$ & & & & & & 6 & 4 & & \\
\hline & $\mathrm{Ag}_{5} \mathrm{Rh}_{1}$ & & & & & & & 4 & 6 & \\
\hline & $\operatorname{Ag}_{6}$ & & & & & & & & 2 & 8 \\
\hline & $\begin{array}{l}\text { Standard } \\
\text { deviation }\end{array}$ & 0.000 & 0.072 & 0.083 & 0.072 & 0.000 & 0.072 & 0.083 & 0.072 & 0.000 \\
\hline \multirow{8}{*}{2} & $\mathrm{Rh}_{6}$ & & & 2 & & & & & & \\
\hline & $\mathrm{Ag}_{1} \mathrm{Rh}_{5}$ & & & & 2 & & & & & \\
\hline & $\mathrm{Ag}_{2} \mathrm{Rh}_{4}$ & & & 6 & 2 & 2 & & & & \\
\hline & $\mathrm{Ag}_{3} \mathrm{Rh}_{3}$ & & & & 4 & 4 & 4 & & & \\
\hline & $\mathrm{Ag}_{4} \mathrm{Rh}_{2}$ & & & & & 2 & 2 & 2 & & \\
\hline & $\mathrm{Ag}_{5} \mathrm{Rh}_{1}$ & & & & & & 2 & & & \\
\hline & $\mathrm{Ag}_{6}$ & & & & & & & 6 & & \\
\hline & $\begin{array}{l}\text { Standard } \\
\text { deviation }\end{array}$ & & & 0.144 & 0.138 & 0.118 & 0.138 & 0.144 & & \\
\hline \multirow{8}{*}{3} & $\mathrm{Rh}_{6}$ & & & & & & & & & \\
\hline & $\mathrm{Ag}_{1} \mathrm{Rh}_{5}$ & & & & & & & & & \\
\hline & $\mathrm{Ag}_{2} \mathrm{Rh}_{4}$ & & & & & 4 & & & & \\
\hline & $\mathrm{Ag}_{3} \mathrm{Rh}_{3}$ & & & & & & & & & \\
\hline & $\mathrm{Ag}_{4} \mathrm{Rh}_{2}$ & & & & & 4 & & & & \\
\hline & $\mathrm{Ag}_{5} \mathrm{Rh}_{1}$ & & & & & & & & & \\
\hline & $\mathrm{Ag}_{6}$ & & & & & & & & & \\
\hline & $\begin{array}{l}\text { Standard } \\
\text { deviation }\end{array}$ & & & & & 0.167 & & & & \\
\hline
\end{tabular}


Table 2. $\mathrm{H}$ absorption energy for the $\mathrm{Ag}_{x} \mathrm{Rh}_{1-x}$ alloys in various sites

\begin{tabular}{|c|c|c|c|c|c|c|c|c|c|c|}
\hline \multirow{2}{*}{$\begin{array}{l}\text { configu } \\
\text { rations }\end{array}$} & \multirow[t]{2}{*}{ sites } & \multicolumn{9}{|c|}{$\mathrm{H}$ absorption energy $[\mathrm{eV}]$} \\
\hline & & $\mathrm{Rh}$ & $\mathrm{Ag}_{0.125} \mathrm{Rh}_{0.875}$ & $\mathrm{Ag}_{0.25} \mathrm{Rh}_{0.75}$ & $\mathrm{Ag}_{0.375} \mathrm{Rh}_{0.625}$ & $\mathrm{Ag}_{0.5} \mathrm{Rh}_{0.5}$ & $\mathrm{Ag}_{0.625} \mathrm{Rh}_{0.375}$ & $\mathrm{Ag}_{0.75} \mathrm{Rh}_{0.25}$ & $\mathrm{Ag}_{0.875} \mathrm{Rh}_{0.125}$ & $\mathrm{Ag}$ \\
\hline \multirow{8}{*}{1} & $\mathrm{Rh}_{6}$ & 0.213 & -0.058 & & & & & & & \\
\hline & $\mathrm{Ag}_{1} \mathrm{Rh}_{5}$ & & 0.093 & -0.133 & & & & & & \\
\hline & $\mathrm{Ag}_{2} \mathrm{Rh}_{4}$ & & & 0.027 & -0.193 & & & & & \\
\hline & $\mathrm{Ag}_{3} \mathrm{Rh}_{3}$ & & & & -0.040 & -0.239 & -0.386 & & & \\
\hline & $\mathrm{Ag}_{4} \mathrm{Rh}_{2}$ & & & & & & -0.098 & -0.280 & & \\
\hline & $\mathrm{Ag}_{5} \mathrm{Rh}_{1}$ & & & & & & & 0.219 & -0.101 & \\
\hline & $\mathrm{Ag}_{6}$ & & & & & & & & 0.978 & 0.734 \\
\hline & All & 0.027 & 0.007 & -0.070 & -0.127 & -0.122 & -0.054 & 0.144 & 0.418 & 0.762 \\
\hline \multirow{8}{*}{2} & $\mathrm{Rh}_{6}$ & & & -0.225 & & & & & & \\
\hline & $\mathrm{Ag}_{1} \mathrm{Rh}_{5}$ & & & & -0.298 & & & & & \\
\hline & $\mathrm{Ag}_{2} \mathrm{Rh}_{4}$ & & & 0.009 & -0.074 & -0.381 & & & & \\
\hline & $\mathrm{Ag}_{3} \mathrm{Rh}_{3}$ & & & & 0.132 & -0.096 & -0.337 & & & \\
\hline & $\mathrm{Ag}_{4} \mathrm{Rh}_{2}$ & & & & & 0.080 & -0.011 & -0.440 & & \\
\hline & $\mathrm{Ag}_{5} \mathrm{Rh}_{1}$ & & & & & & 0.320 & & & \\
\hline & $\mathrm{Ag}_{6}$ & & & & & & & 1.066 & & \\
\hline & All & & & -0.003 & -0.050 & -0.093 & 0.066 & 0.356 & & \\
\hline \multirow{8}{*}{3} & $\mathrm{Rh}_{6}$ & & & & & & & & & \\
\hline & $\mathrm{Ag}_{1} \mathrm{Rh}_{5}$ & & & & & & & & & \\
\hline & $\mathrm{Ag}_{2} \mathrm{Rh}_{4}$ & & & & & -0.227 & & & & \\
\hline & $\mathrm{Ag}_{3} \mathrm{Rh}_{3}$ & & & & & & & & & \\
\hline & $\mathrm{Ag}_{4} \mathrm{Rh}_{2}$ & & & & & 0.394 & & & & \\
\hline & $\mathrm{Ag}_{5} \mathrm{Rh}_{1}$ & & & & & & & & & \\
\hline & $\mathrm{Ag}_{6}$ & & & & & & & & & \\
\hline & All & & & & & 0.073 & & & & \\
\hline
\end{tabular}



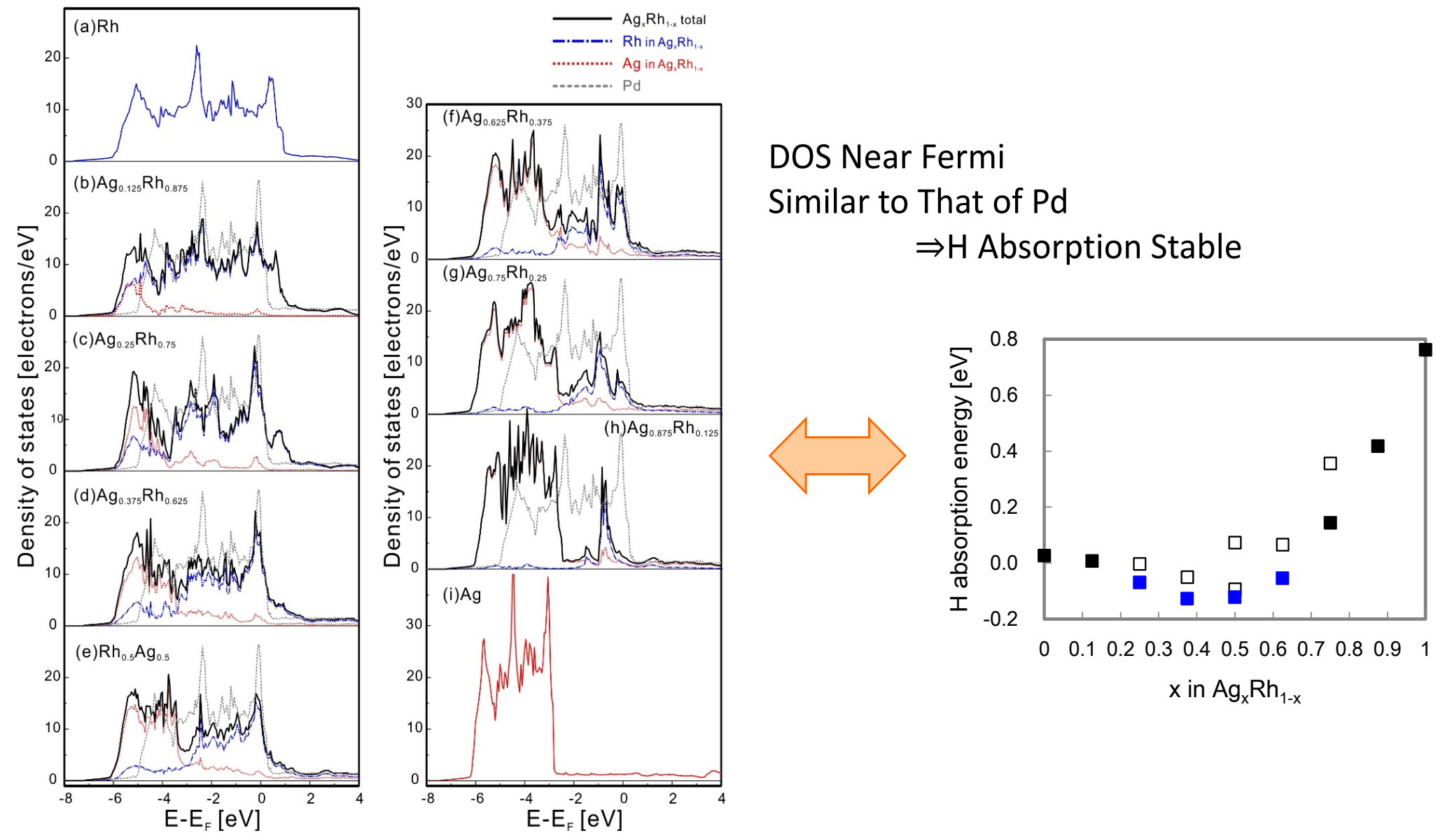